\title{
Linear Control Method for Arch Ring of Oblique-Stayed Buckle Cantilever Pouring Reinforced Concrete Arch Bridge
}

\author{
Zengwu Liu (iD, Jianting Zhou (D), Yuexing Wu ${ }^{D}$, Xing You, and Yinghao Qu \\ State Key Laboratory of Mountain Bridge and Tunnel Engineering, Chongqing Jiaotong University, Chongqing 400074, China \\ Correspondence should be addressed to Jianting Zhou; jtzhou@cqjtu.edu.cn
}

Received 29 October 2020; Revised 1 April 2021; Accepted 8 April 2021; Published 16 April 2021

Academic Editor: DongDong Ge

Copyright (C) 2021 Zengwu Liu et al. This is an open access article distributed under the Creative Commons Attribution License, which permits unrestricted use, distribution, and reproduction in any medium, provided the original work is properly cited.

Yelang Lake Bridge is the largest cantilevered single-chamber reinforced concrete arch bridge in China, with a net span of $210 \mathrm{~m}$. In this article, an equation for positioning the height of the formwork before pouring of the arch ring segment was derived, which was suitable for the construction control of the long-span reinforced concrete arch bridge such as the Yelang Lake Bridge. The arch ring segment elevation calculation equation was derived under the two typical working conditions that the concrete pouring of the arch ring segment is completed and the buckle cable and anchor cable tensioning are completed. In addition, two typical working conditions of arch ring segment concrete pouring and cable tensioning were evaluated. Then, a new type of cradle and loading test of the cradle, which meet the requirements of the long segment pouring of the arch ring, were introduced. Finally, the measurement deviation during the construction of the arch segment was analyzed. The linear control results of the arch ring showed that the arch ring segment elevation calculation formula could effectively ensure the accuracy of the arch ring segment construction process under the two typical conditions of completion of concrete pouring of the arch ring segment and completion of the buckle and anchor cable tensioning. The maximum deviation is only $3.1 \mathrm{~mm}$. The line shape after the completion of the arch ring construction was in good agreement with the target line shape, and the deviation between the measured value and the target value was only $2.5 \mathrm{~cm}$, which met the engineering requirements.

\section{Introduction}

Arch bridge has a long history and is one of the important bridge types. In the western mountainous areas of China, due to the complex terrain, arch bridges are a highly competitive bridge type. In addition, the reinforced concrete box arch bridge has the advantages of large structural rigidity, low cost, and good performance in the later stage. Reinforced concrete arch bridge construction methods mainly include the bracket pouring method (see Figure 1), arch rib precast hoisting method (see Figure 2), cantilever pouring method (see Figure 3), and combined construction method. The bracket pouring method is suitable for smallspan arch bridges because it needs to set up the brackets before pouring the concrete of the arch ring. The arch rib prefabrication hoisting method requires a special site to manufacture arch rib segments, and the integrity of the arch bridge constructed by this method is poor. As a new construction method of arch bridge construction, the cablestayed buckle cantilever pouring reinforced concrete box arch bridge has good environmental adaptability and the completed arch bridge has good integrity. The combined construction method is also called the construction method of cantilever pouring combined with stiff skeleton. In this method, the arch foot section adopts cantilever pouring, and the arch top section first erects the stiff skeleton before concrete is poured. This method not only has the advantages of the cantilever pouring method but also has another three advantages: (i) shortening the length of the cantilever pouring, (ii) reducing the weight of the cantilever, and (iii) increasing the safety of construction.

Many scholars have studied the initial cable force of cable structure bridges. The methods proposed in the literature were used to determine cable force of long-span bridges $[1,2]$, mainly including the optimization method, force equilibrium method, zero displacement method, and 


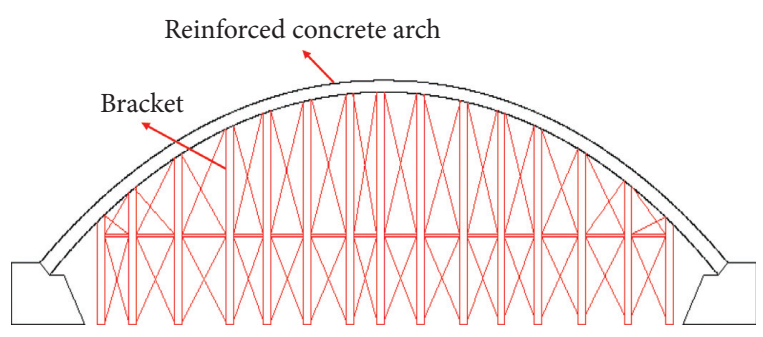

FIGURE 1: Bracket pouring method.

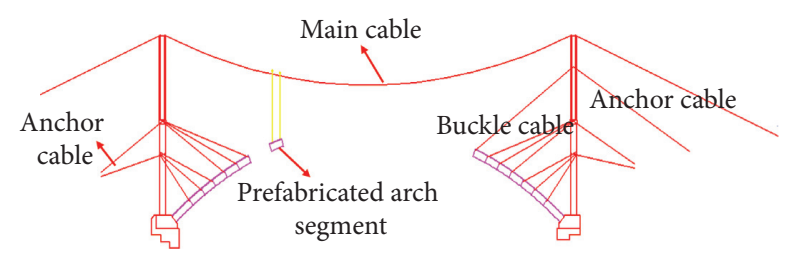

FIgURE 2: Arch rib prefabricated hoisting method.

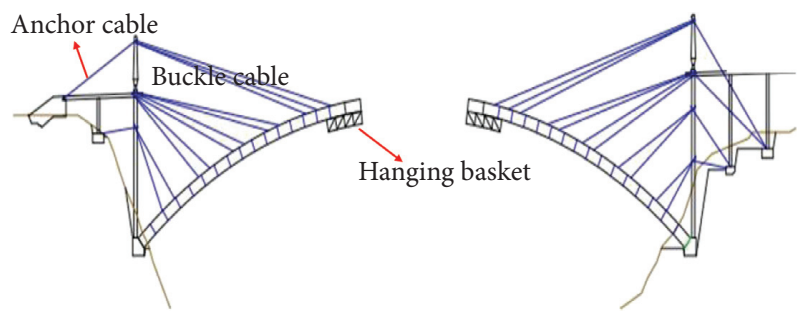

FIgURE 3: Cantilever pouring method.

unit load method. In the optimization method, the cable force is determined based on certain functions that are related to structural efficiency or economy. Kasuga et al. [3] proposed some optimized criteria and obtained the optimum adjusting cable force by minimizing the amount of work due to these forces. Wu et al. [4] presented a method along with its software development to simulate different construction stages of cable-stayed bridge and provided the initial cable force for each construction stage. Bruno et al. [5] proposed a new design method to evaluate the optimum configuration of network arch bridge. Elrehim et al. [6] presented a geometrical structural optimization method to study the deck of concrete arch bridge by Genetic Algorithms technique. Sung et al. [7] utilized the constrained minimization method for the optimum solution of cable force of the Mau-Lo Hsi Bridge. Wang et al. [8] set up a finite element computation procedure at different erection stages during construction using the cantilever method. The procedure can be successfully applied in determining the initial shape of bridge structures during the erection procedure. Then, the initial cable force of the bridge can be achieved. Granata et al. [9] put forward a procedure for determining the initial cable force, considering the geometric nonlinearity of stayed cable through the Dischinger equivalent elastic modulus. Fabbrocino et al. [10] developed a procedure for the optimization of cable force in order to achieve the desired bending moment distribution through the application of a self-equilibrated state of stress induced by the optimum pretensioning cable force. Song et al. [11] proposed an optimization method to determine the pretensioning cable force in a long-span bridge considering the counterweight. Li et al. [12] determined the initial cable force of long-span concrete-filled steel tube (CFST) arch bridge based on influence matrix and linear programming methods. Nakamura et al. [13] designed a new type of hybrid bridge (cable-arch bridge) and optimized the cable force status. Negrão et al. [14] described an analytical sensitivity analysis and optimization implementation for cable-stayed bridge design. Kang et al. [15] constructed a model of cablearch bridge and investigated its static behavior using the finite element method and experimental test. Baldomir et al. [16] described an optimization problem of cable crosssection of a cable-stayed bridge considering constraints of cable stress and deck displacement. Martins et al. [17] used an entropy-based optimization algorithm to find the initial cable force of a concrete cable-stayed bridge. Dai and Wang [18] proposed an optimization calculation method to optimize the initial cable force of cable-stayed arch bridge in arch rib cantilever erecting.

In the force equilibrium method, the cable force is determined by utilizing the idea of force equilibrium, which is considered as independent variable for achieving target bending moments along the girder.

The final cable force is calculated iteratively. Chen et al. [19] proposed the force equilibrium method to determine the initial cable force of prestressed concrete cable-stayed bridge. In the zero displacement method, the configuration of zero deflection along the girder is taken as the target and the cable forces are obtained by iterative calculation. Wang et al. [20] used the zero displacement method to determine the cable forces and the initial configuration of the bridge. The method is based on the idea that the stayed cables transform the structural system of girder into a rigidly supported continuous beam. Zhang and Au [21] optimized the zero displacement method using a Kriging surrogate model. The calibration method was used to identify reasonable initial forces in the critical stayed cables. The unit load method (ULM) was used to determine the initial cable force by achieving the desired moment distribution at specific degrees of freedom (DOF). Janjic et al. [22] proposed the ULM for determining the cable force of cable-stayed bridges. The system of linear equations of desired moments was established for each DOF, and the initial cable force was then determined directly by this system. In addition, it is also possible to obtain the desired geometric shape of the arch at the end of construction to solve the initial cable force; for example, Granata et al. [23] used the partial elastic scheme method to obtain the initial cable force of cantilever casting concrete arch bridge. Tian et al. [24] used stress balance and influence matrix methods to determine the initial cable force of concrete arch bridge.

In summary, many scholars have studied the calculation methods of the initial cable tension of cable-stayed bridges, CFST arch bridges, and cantilevered concrete arch bridges. After the initial cable force is determined for the cantilever concrete arch bridge, the deformation of the arch ring segment during the cantilever casting process can be obtained by using the finite element program, which can 
provide guidance for the actual construction of the arch ring segment. However, few scholars have conducted research on the positioning of the formwork before the concrete pouring of the arch ring segment and the calculation of the arch ring segment elevation under two typical conditions of completion of concrete pouring of the arch ring segment and completion of buckle and anchor cable tension.

The Yelang Lake Bridge has a net span of $210 \mathrm{~m}$. As the largest cantilevered single-chamber reinforced concrete arch bridge in China, the construction is difficult due to the longcantilevered section. With the increase of the cantilever pouring length and weight, the existing cradle is prone to excessive stress on the rods and excessive deflection of the cantilever end, which is difficult to meet the requirements of cantilever pouring, resulting in a corresponding increase in the difficulty of arch ring linear control.

This article introduced a new type of hanging basket that meets the requirements of long-section cantilever construction and derived the formwork elevation positioning equation before the arch ring segment pouring, which is suitable for the construction control of the long-span reinforced concrete arch bridge. The arch ring segment elevation calculation equation under the two typical working conditions that the concrete pouring of the arch ring segment is completed and the buckle cable and anchor cable tensioning are completed was derived. The two typical working conditions of arch ring segment concrete pouring and cable tensioning were evaluated to ensure that the line shape of the arch ring segment during the cantilever pouring process was consistent with the target value.

\section{Linear Control Method of Arch Ring Construction Process of Arch Bridge}

The linear control of the cantilever pouring of the arch ring is an important content of this bridge. In order to meet the line shape of the arch ring segment during the cantilever pouring stage and the tensioning stage to be consistent with the target line shape, it is necessary to calculate the elevation of the arch ring segment before the concrete pouring of the arch ring segment and the arch ring segment elevation under the two typical conditions of completion of concrete pouring of the arch ring segment and completion of the buckle and anchor cable tensioning and put forward the calculation equation.

2.1. Formwork Positioning Elevation Calculation before Concrete Pouring of Arch Ring Segment. For a box arch bridge of equal height, the coordinate system is established (see Figure 4).

In the actual cantilever pouring construction process of the arch ring, when the template is positioned before concrete pouring of segment $i$ of the arch ring, it is often controlled by the elevation of the bottom edge of the cantilever end of the arch ring. For the XOY coordinate system, the calculation equation for the positioning elevation of the arch ring segment $i$ template is shown in

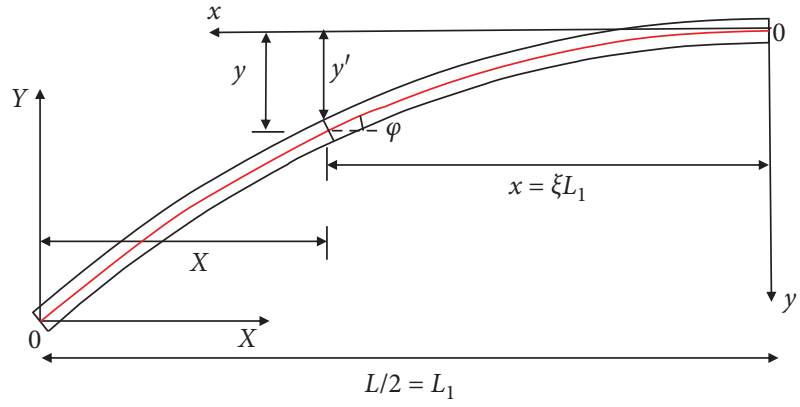

FIgURE 4: Schematic diagram of arch circle coordinates.

$$
H_{1}^{i}=H_{2}^{i}-\frac{h}{2} \times \cos \varphi+f_{1}^{i}+f_{2}^{i},
$$

where $H_{1}^{i}$ is the positioning elevation of arch ring $i$ segment template (unit: $\mathrm{m}$ ); $H_{2}^{i}$ is the design elevation of the section center of section $i$ of the arch ring (unit: $\mathrm{m}$ ); $f_{1}^{i}$ is the design precamber value of section $i$ of arch ring (unit: $\mathrm{m}$ ); $f_{2}^{i}$ is the theoretical deformation value of the hanging basket when pouring the concrete of section $i$ (unit: $\mathrm{m}$ ); $h$ is the thickness of main arch ring (unit: $\mathrm{m}$ ); $\varphi$ is the horizontal inclination of arch ring section (unit: degree). The horizontal distance between the template positioning point and the center of the arch foot section is shown in Equation (2). The unit of $X^{\prime}$ is $\mathrm{m}$.

$$
X^{\prime}=X+\frac{h}{2} \times \sin \varphi
$$

2.1.1. Design Elevation Calculation of Top Edge of Arch Ring. The elevation of any section of the main arch ring can be calculated according to its arch axis equation, section height, and arch ring section inclination. In the XOY coordinate system shown in Figure 4, the arch axis equation of the arch ring is shown in Equation (3). The unit of $y$ is $\mathrm{m}$.

$$
y=\frac{f}{m-1} \times(\cosh (k \times \xi)-1),
$$

where $m$ is the arch axis coefficient; $k$ is the coefficient $\left(k=\ln \left(m+\sqrt{m^{2}-1}\right)\right) ; f$ is the calculated vector height (unit: $\mathrm{m}$ ); $\xi$ is the coefficient $(\xi=2 x / L)$; Lis the calculated span (unit: $\mathrm{m}$ ).

The equation for calculating the horizontal inclination at position $x$ from the vault is shown in

$$
\tan \varphi=\frac{2 \times f \times k \times \sinh (k \times \xi)}{L \times(m-1)} .
$$

When the arch section is of equal height, the $y^{\prime}$ coordinate of the upper edge of the section at the position $x$ from the dome (upper edge of the arch back) is shown in Equation (5). The unit of $y^{\prime}$ and $x$ is $\mathrm{m}$.

$$
y^{\prime}=y-\frac{h}{2} \times \cos \varphi .
$$


The corresponding $x^{\prime}$ coordinate is shown in Equation (6). The unit of $x^{\prime}$ is $\mathrm{m}$.

$$
x^{\prime}=x+\frac{h}{2} \times \sin \varphi .
$$

However, during arch bridge construction, the origin of the coordinate system is often established at the center of the arch toe section, as shown in the XOY coordinate system in Figure 4. At this time, the arch axis equation changes from Equations (3) to (7), and the coordinates of the top edge of the arch ring (upper edge of the arch back) are $X^{\prime}, Y^{\prime}$, as shown in Equations (8) and (9) The unit of $Y, X^{\prime}$, and $Y^{\prime}$ is $m$.

$$
\begin{aligned}
Y & =f-\frac{f}{m-1}\left[\cosh \left(k \times\left(1-\frac{2 X}{L}\right)\right)-1\right], \\
Y^{\prime} & =Y+\frac{h}{2} \times \cos \varphi, \\
X^{\prime} & =X-\frac{h}{2} \times \sin \varphi .
\end{aligned}
$$

2.1.2. Design Elevation $\left(H_{2}^{i}\right)$ and Design Precamber $\left(f_{1}^{i}\right)$. $H_{2}^{i}$ and $f_{1}^{i}$ can be inquired through the design drawings. Generally, the precamber value $f_{1}^{i}$ of the arch bridge is composed of the deformation value (vertical displacement) caused by the bridge weight, concrete shrinkage and creep, and vehicle load.

\subsubsection{Calculation of the Theoretical Deformation Value of the} Hanging Basket. $f_{2}^{i}$ is the theoretical deformation value of the hanging basket when the pouring segment $i$ of the arch ring, and the method of obtaining $f_{2}^{i}$ is as follows:

(1) Based on the precompression load test of the cradle in Section 3.4 of this article, the measured deformation value of the cradle under the graded load was recorded, and the linear fitting method was used to obtain the relationship between the deformation of the cradle and the load, as shown in

$$
f_{21}^{i}=\frac{a}{188.6} \times G_{i}+b
$$

where $a$ and $b$ are constant terms; $G_{i}$ is the weight of segment $i$ of the arch ring; 188.6 is the weight of No. 2 section of the arch ring (unit: $\mathrm{t}$ ). The unit of $f_{21}^{i}$ is $\mathrm{m}$.

(2) The finite element model of the new triangular truss cradle was established when pouring the concrete of section $i$ of the arch ring to obtain the deformation value $f_{22}^{i}$ of the cradle. The concrete load of section $i$ of the arch ring was simulated by linear load, and the diaphragm was simulated by a concentrated force. The finite element model of the hanging basket is shown in Figure 5.

(3) The measured deformation value $f_{2}^{\prime i-1}$ of the travel basket of segment $i-1$ of the arch ring was used as the theoretical deformation value $f_{23}^{i}$ of the travel basket of segment $i$ of the arch ring.

(4) The theoretical deformation values of the hanging basket in (1)-(3) were compared, and the maximum value was selected as the theoretical deformation value of the basket in segment $i$ of the arch ring.

$$
f_{2}^{i}=\operatorname{MAX}\left(f_{21}^{i}, f_{22}^{i}, f_{23}^{i}\right) \text {. }
$$

2.2. Elevation Calculation after Concrete Pouring of Arch Ring. After the concrete of the arch ring is poured, the hanging basket deforms downwards. If the actual deformation of the hanging basket after concrete pouring is $f_{2}^{\prime} i$, the height of the top edge of the arch ring segment $i$ after concrete pouring is shown in Equation (12). The unit of $H_{3}^{i}$ and $f_{2}^{\prime}$ is $\mathrm{m}$.

$$
H_{3}^{i}=H_{2}^{i}+\frac{h}{2} \times \cos \varphi+f_{1}^{i}+f_{2}^{i}-f_{2}^{\prime i}
$$

It can be seen from Equation (12) that the theoretical deformation of the hanging basket is equal to the measured deformation of the hanging basket when $f_{2}^{i}=f_{2}^{\prime}$. At this time, the elevation of the top edge of the arch segment $i$ can be simplified as shown in

$$
H_{3}^{i}=H_{2}^{i}+\frac{h}{2} \times \cos \varphi+f_{1}^{i} .
$$

Normally, the theoretical deformation of the hanging basket is not equal to the measured deformation of the hanging basket $\left(f_{2}^{i}=f_{2}^{\prime i}\right)$. The difference between $f_{2}^{i}$ and $f_{2}^{\prime i}$ can be set as $\Delta f_{2}$, as shown in

$$
\Delta f_{2}=f_{2}^{i}-f_{2}^{\prime i}
$$

When $f_{2}^{i}>f_{2}^{\prime i}\left(\Delta f_{2}>0\right)$, it means that the theoretical deformation value of the basket is too large. When $f_{2}^{i}<f_{2}^{\prime i}$ $\left(\Delta f_{2}<0\right)$, it means that the theoretical deformation value of the basket is too small. However, the elevation of the top edge of the arch ring segment $i$ in the above two situations can be expressed by

$$
H_{3}^{i}=H_{2}^{i}+\frac{h}{2} \times \cos \varphi+f_{1}^{i}+\Delta f_{2} .
$$

The measurement of each arch ring segment after pouring is very important, and the following points should be noted.

(1) The measurement should be carried out during the period when the temperature is relatively stable, and the temperature field of the arch section is relatively stable. The temperature during measurement should be the same as the temperature of the arch ring segment before pouring; otherwise, the influence of temperature change should be considered.

(2) In order to reduce the errors caused by measuring instruments, high-precision instruments should be used for measurement. 


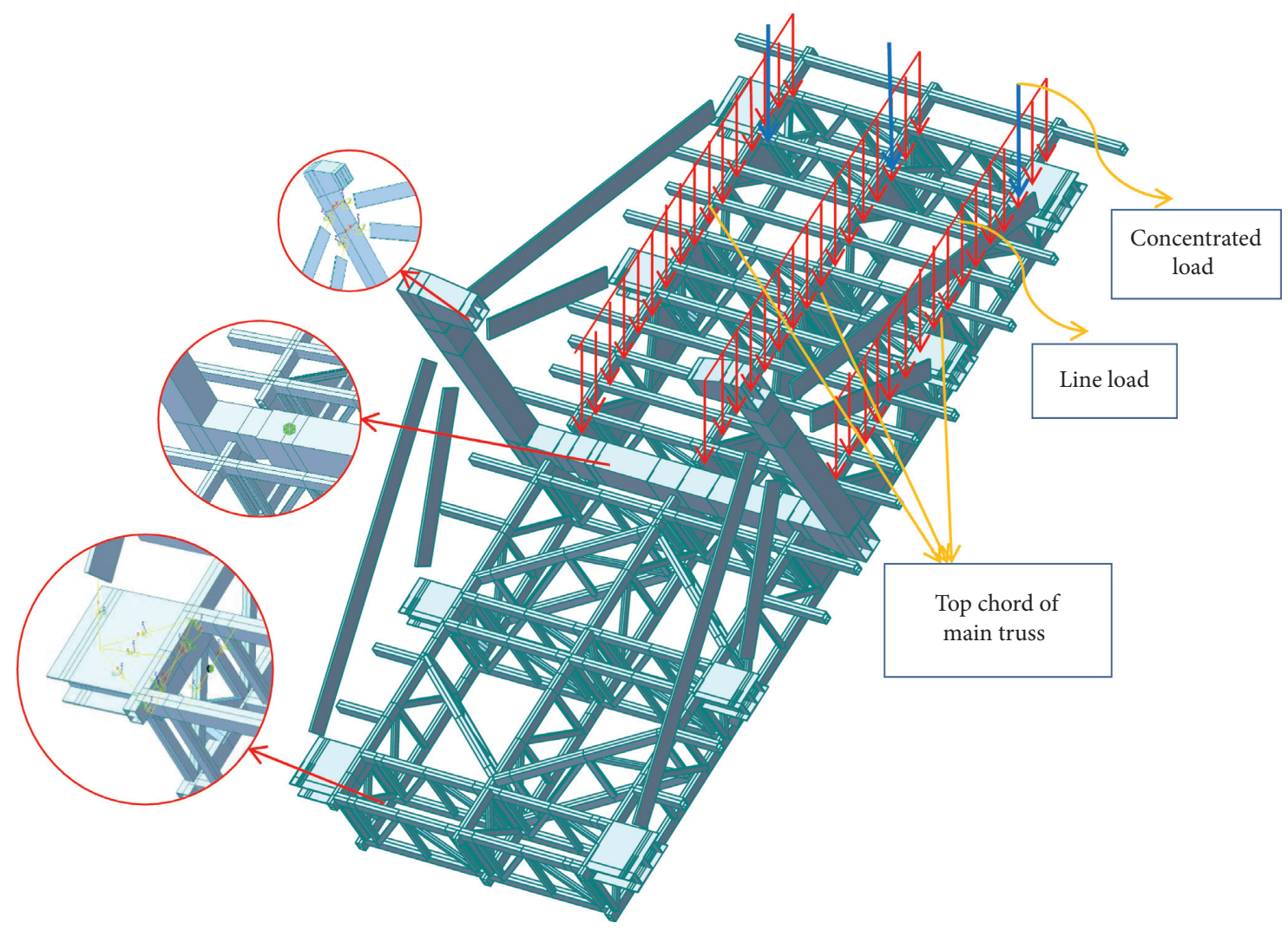

FIgURE 5: The finite element model of the hanging basket.

(3) The error of the measurement personnel should be eliminated and multiple measurements should be performed.

By measuring the elevation of the arch ring segment after pouring, the deviation between the actual deflection value of the arch ring segment $i$ and the target value can be known as follows:

$$
\delta^{i}=H_{4}^{i}-H_{3}^{i},
$$

where $\delta^{i}$ is the deviation of the actual deflection value of the arch ring segment $i$ pouring from the target value (unit: $\mathrm{m}$ ); $H_{4}^{i}$ is the target elevation value of the arch ring segment $i$ after pouring (unit: $\mathrm{m}$ ).

\subsection{Elevation Calculation after Buckle and Anchor Cable Are} Tensioned. After the arch concrete reaches the allowable strength, the buckle and anchor cables can be symmetrical, graded and stretched synchronously according to the calculated buckle and anchor cable forces. Due to the cable force, the arch ring segment is deflected upwards. The calculation equation for the elevation of the top edge of the arch ring segment $i$ after the tension of the buckle and anchor cables is completed is shown in

$$
H_{5}^{i}=H_{2}^{i}+\frac{h}{2} \times \cos \varphi+f_{1}^{i}+\delta^{i}+\Delta f_{3},
$$

where $H_{5}^{i}$ is the elevation of the top edge of the arch ring segment $i$ after the buckle and anchor cable tension is completed (unit: $\mathrm{m}$ ). $\Delta f_{3}$ is the deformation (vertical displacement) of the arch ring segment $i$ caused by the tension of the buckle and anchor cables, which can be calculated by finite element program. In summary, the positioning elevation of the formwork before concrete pouring of the arch ring segment, the elevation after the completion of the arch ring concrete pouring, and the elevation after cable tensioning can be calculated by Equations (1), (15), and (17),1 15respectively.

During the cantilever pouring of the arch ring, the deformation (vertical displacement) of the arch ring segment consists of two parts (the downward deformation when concrete is poured and the upward deformation when the buckle and anchor cables are tensioned). As long as the deformation (vertical displacement) of these two parts is consistent with the target deformation (vertical displacement) calculated by the finite element, it can be ensured that the line shape during the construction of the arch and the line shape after the construction is consistent with the target line shape.

2.4. Calculation of Installation Elevation of the Stiff Skeleton on the Top of the Arch Ring. There is a stiff skeleton at the top of the arch, and the installation elevation of the stiff skeleton needs to be calculated, as shown in

$$
H_{6}^{i}=H_{2}^{i}+\frac{h^{\prime}}{2} \times \cos \varphi+f_{1}^{i}+\delta^{\prime},
$$

where $H_{6}^{i}$ is the stiff skeleton installation elevation (unit: $\mathrm{m}$ ); $\delta^{\prime}$ is the stiff skeleton deformation (vertical displacement) (unit: $\mathrm{m}$ ); $h^{\prime}$ is the height of the stiff skeleton section (unit: $\mathrm{m})$. 


\section{Project Example}

3.1. Bridge Description. The Yelang Lake Bridge spans Yelang Lake and is located in Guizhou Province, China. The total length of the bridge is $391.4 \mathrm{~m}$, and the main bridge is a deck-type reinforced concrete box arch bridge with a net span of $210 \mathrm{~m}$ (see Figure 6). The arch rib is a concrete catenary structure with a box cross-section of the same height. Its net span $L_{0}$, net height $f_{0}$, and rise-span ratio $f_{0} / L_{0}$ are $210 \mathrm{~m}, 42 \mathrm{~m}$, and $1 / 5$, respectively. There is a $30.944 \mathrm{~m}$ steel stiff frame at the top of the arch ring. It is a catenary curve with an arch axis coefficient $m$ of 1.67. The arch ring is a single-box single-chamber section with a width of $7.0 \mathrm{~m}$ and a height of $3.5 \mathrm{~m}$. The thickness of the top and bottom of the section of the arch at the foot (see Figure 7) of the arch is gradually changed from $80 \mathrm{~cm}$ to $40 \mathrm{~cm}$, and the thickness of the web is gradually changed from $80 \mathrm{~cm}$ to $50 \mathrm{~cm}$. The thickness of the top and bottom of the remaining section of the arch ring (see Figure 8 ) is $40 \mathrm{~cm}$, and the thickness of the web is $50 \mathrm{~cm}$. The longest segment of the arch is No. 2, and its length and the maximum weight are $7.98 \mathrm{~m}$ and $1886 \mathrm{kN}$. The column on the arch adopts a double-column type. Above the column is a prestressed concrete hollow board with a span of $13.2 \mathrm{~m}$, and the height of the board is $0.7 \mathrm{~m}$.

3.2. Main Arch Ring Construction Plan. The main arch ring of Yelang Lake Bridge is constructed by the combination method of cantilever pouring and rigid skeleton. No. 1 section of the arch ring is cast-in-place with a bracket, and sections $2-14$ of the arch ring adopt cantilever pouring. The outer concrete was poured after the rigid skeleton on the top of the arch ring was installed. The construction process of arch sections $2-14$ was as follows:

(1) The arch ring segment $i$ buckle cable and anchor cable were tensioned

(2) The hanging basket to the pouring position of segment $i+1$ of the arch ring was moved

(3) The concrete of segment $i+1$ of the arch ring was poured

The construction process of the main arch ring of the Yelang Lake Bridge is shown in Figures 9 to 14.

The pouring of the outer concrete on the top of the arch ring adopts the following scheme: The arch ring bottom plate and $1 / 2$ web concrete in two working faces were simultaneously symmetrically poured. After the concrete reaches its strength, the arch box roof and $1 / 2$ web concrete in two working faces were symmetrically poured. The vertical and horizontal pouring sequence of the outer concrete on the top of the arch ring is shown in Figures 13 and 14.

3.3. New Triangular Truss Hanging Basket. In order to meet the characteristics of long arch segments and large weight, the project department proposed a new type of triangular truss hanging basket (see Figures 15 and 16), which mainly included the main truss load-bearing system. The loadbearing system of the main truss was composed of section steel with C-shaped hooks set on both sides. The top of the C-shaped hook could move along the track, which was provided with a connecting plate. The connecting plate was connected with the front basket and the rear basket of the main truss load-bearing system through many cable-stayed steel slings, and the rear basket was provided with a reverse roller device. Load-bearing anchor rods were set on the main truss load-bearing system.

\subsection{Preloading Test of the New Triangular Truss Hanging} Basket. After the construction of No. 1 section of the arch ring was completed, the hanging basket was installed and the hanging basket load test was carried out. The purpose of the load test was to check whether the force of the hanging basket met the requirements and eliminate the inelastic deformation of the cradle. The load test could also obtain the elastic deformation value of the stage loading of the hanging basket, and mathematical methods were used to process the elastic deformation value of the graded loading to obtain the deformation relational expression of the hanging basket.

The load test of the hanging basket was as follows:

(1) The load test was carried out by setting vertical anchor cables on the ground and using vertical cables to pull the cradle backward.

(2) Construct vertical anchor cables on the ground below the hanging basket (see Figure 17). The anchor cable adopted $6 \varphi 15.24 \mathrm{~mm}$ steel strand. The length of the vertical anchor cable was $17 \mathrm{~m}$, and the length of anchoring in the rock is not less than $10 \mathrm{~m}$. The function of the vertical anchor cable was to fix the 2I40b I-steel box on the concrete base and pull the vertical anchor cable to make the 2I40b I-steel box tightly fixed on the concrete base $(50 \times 50 \times 50 \mathrm{~cm})$.

(3) After the hanging basket was installed, two 2I40b I-beam boxes on the top surface of the hanging basket were fixed, and the leveling steel box on the top surface of the 2I40b type I-steel box was welded (see Figure 18).

(4) The vertical cables were installed, and the single vertical cable adopted the $4 \varphi 15.24 \mathrm{~mm}$ steel strand. The lower end of the vertical cable was anchored to the steel box on the top surface of the concrete base, and the upper end was anchored to the leveling steel box on the top surface of the hanging basket. The upper end of the vertical cable was the tension end, and the pulling force was applied by the Jack method to make the hanging basket obtain a downward force.

(5) The segment with the heaviest arch ring was segment $2(1886 \mathrm{kN})$. The weight of No. 2 segment of the arch ring to tension the vertical cables in grades was used with the order of $30 \% \longrightarrow 50 \% \longrightarrow 70 \% \longrightarrow 100 \% \longrightarrow$ $110 \% \longrightarrow 120 \%$. The deflection value of the front end of the hanging basket while loading in stages was observed (see Figures 19 and 20). Whether there was any abnormality in the structure of the hanging basket was checked, and there was no problem, and 


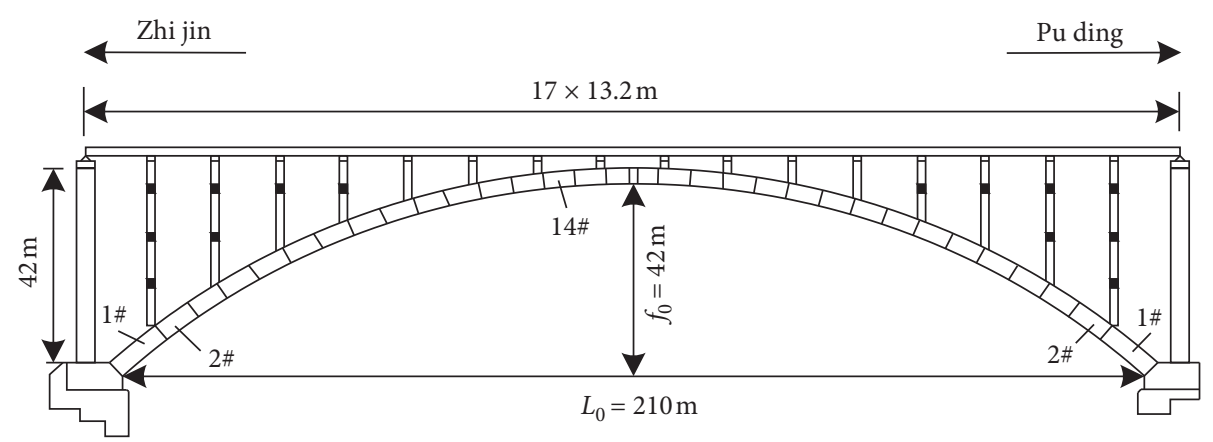

Figure 6: The general layout of the bridge (units: (m).

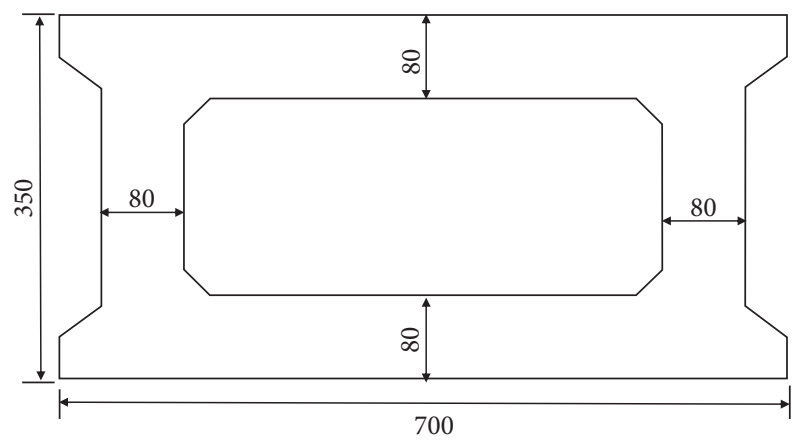

FIgure 7: The arch foot section (units: $\mathrm{cm}$ ).

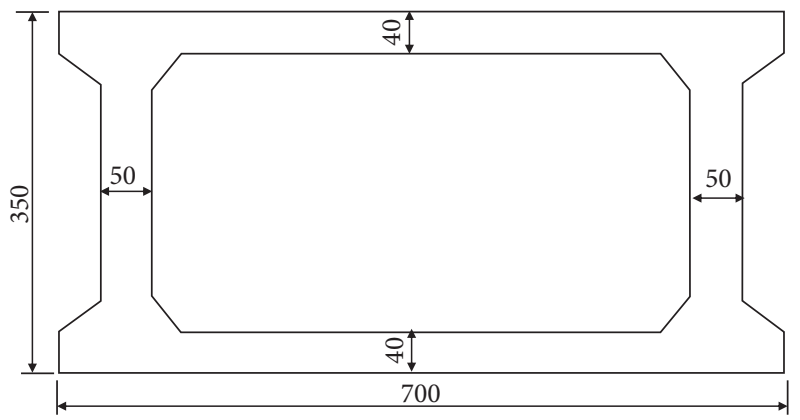

FIGURE 8: Standard section of the arch (units: $\mathrm{cm}$ ).

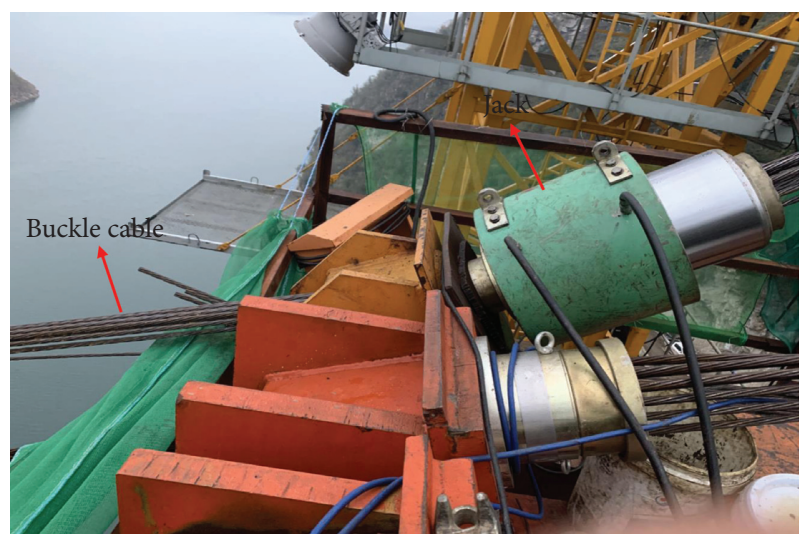

Figure 9: Tension arch ring segment $i$ buckle cable and anchor cable. the data were recorded before proceeding to the next level of loading., Finally, $120 \%$ of the weight of the arch ring No. 2 segment was loaded. If the force of the hanging basket was in good condition, it started to unload in stages after a 60-minute pause.

It could be seen from Figure 20 that the maximum measured deformation value of the front end of the hanging basket was less than $20 \mathrm{~mm}$, and the maximum difference between the measured deformation value and the finite element simulation calculated deformation value was $5 \mathrm{~mm}$, which appeared in the $120 \%$ loading stage. The overall change trend of the measured deformation value was consistent with the finite element simulation value, and the deformation and the load were approximately linear, so the linear relationship between loading and deformation of the hanging basket could be fitted.

\section{Linear Monitoring Results of Cantilever Pouring of Arch Ring}

4.1. Finite Element Simulation. The arch ring of Yelang Lake Bridge was simulated by beam element. The buckle and anchor cables were simulated by truss elements, and the elastic modulus was modified by the Ernst formula to consider the effects of nonlinearity. The arch foot adopted general support simulation and restrained all DOF. The arch foot support adopted the node elastic support simulation. The rigid connection simulation was adopted between the buckle cable, the arch ring, and the buckle tower. The anchor cable, buckle tower, and ground were simulated by rigid connection and consolidation, respectively. The arch ring diaphragm adopted concentrated load simulation; the Yelang Lake Bridge used triangular truss hanging baskets for cantilever pouring. The total weight of the cradle was about $800 \mathrm{kN}$, and the hanging baskets used centralized load simulation. The finite element model was shown in Figure 21.

Based on the finite element simulation, the vertical deformation of the concrete pouring and tensioning of the arch ring segment could be obtained. For example, the vertical displacement of section No. 8 of the arch ring was $-98 \mathrm{~mm}$ when concrete was poured, and the vertical deformation after tensioning the buckle cable and anchor cable was $108 \mathrm{~mm}$ (see Figures 22 and 23). 


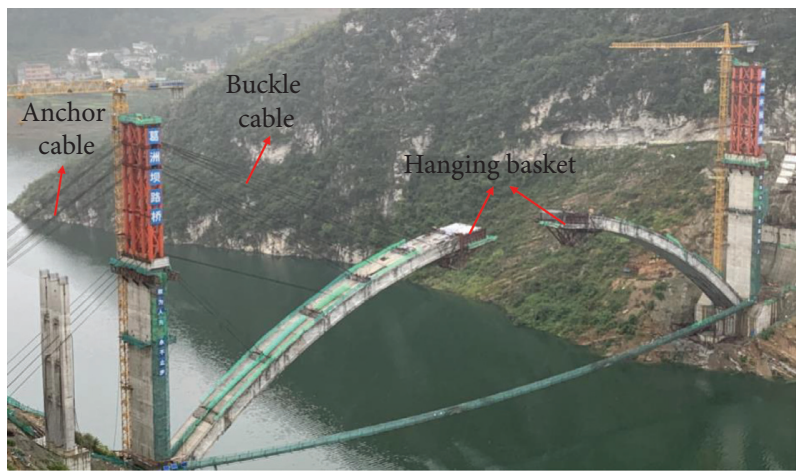

Figure 10: Move the hanging basket to the pouring position of segment $i+1$ of the arch ring.

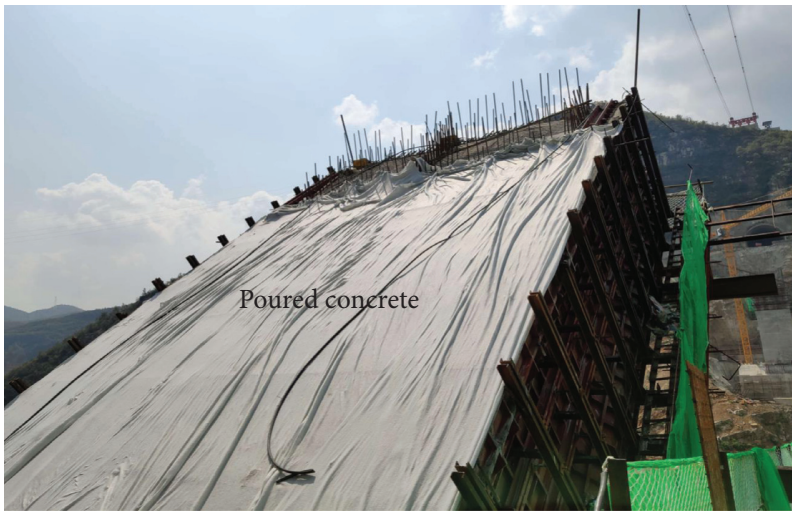

FIgURE 11: The concrete of segment $i+1$ of the arch ring after pouring.

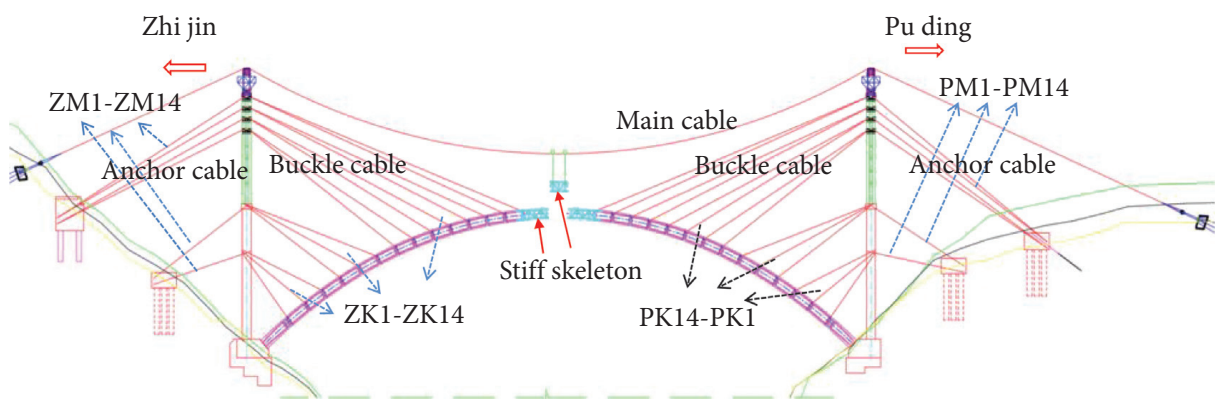

FIGURE 12: Install the stiff skeleton at the top of the arch ring of the Yelang Lake Bridge.

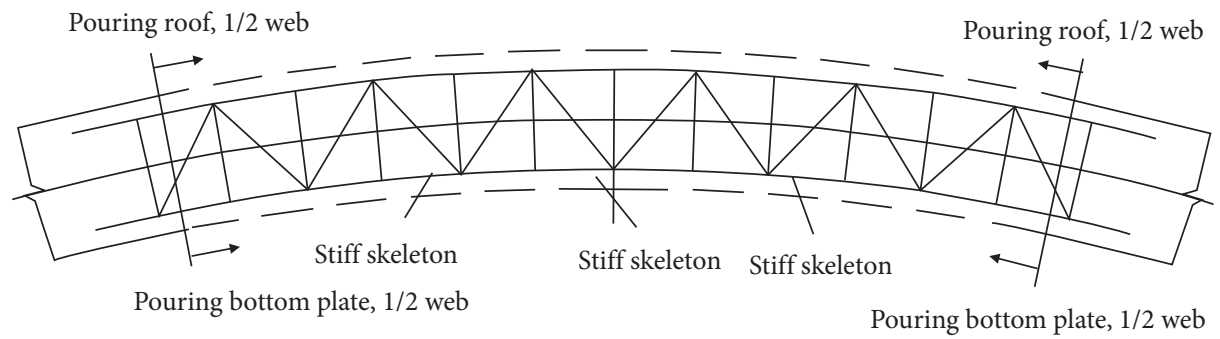

FIgURE 13: Sequence diagram of the longitudinal pouring of the outer concrete on the top of the arch ring. 

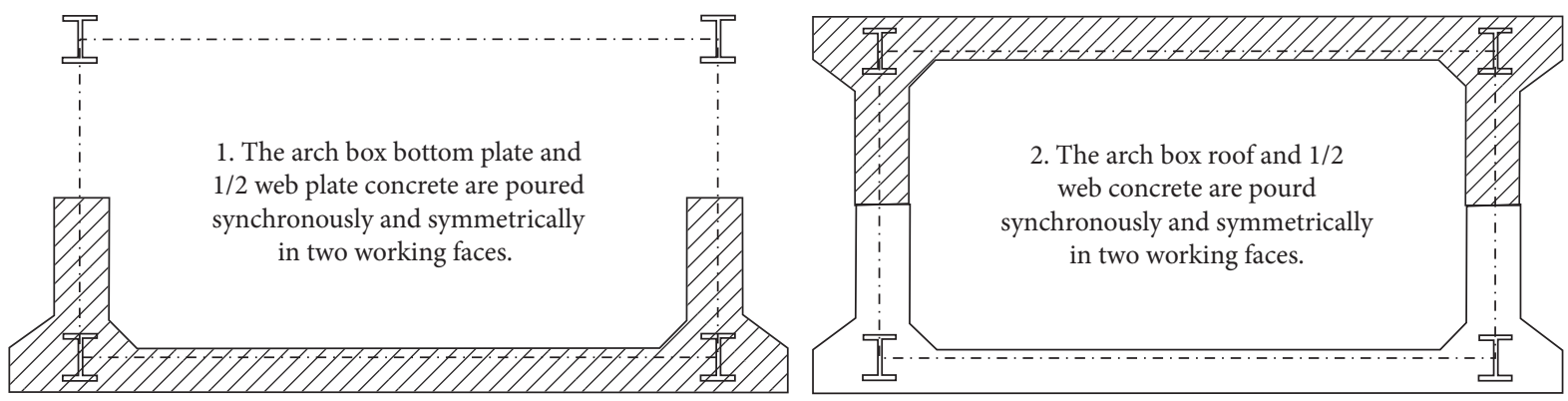

Figure 14: Sequence diagram of the lateral pouring of the outer concrete on the top of the arch ring.

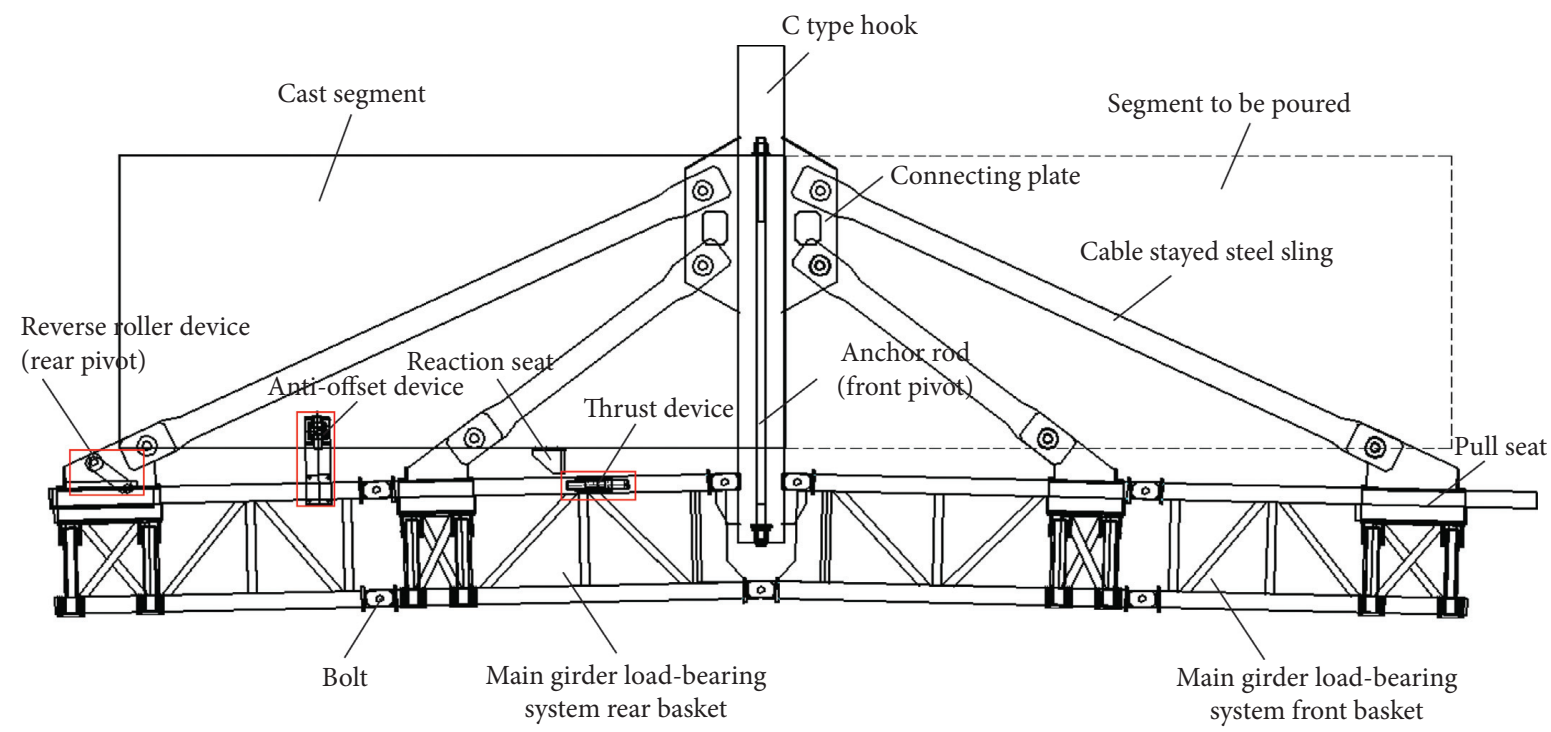

Figure 15: Front view of new triangular truss hanging basket.

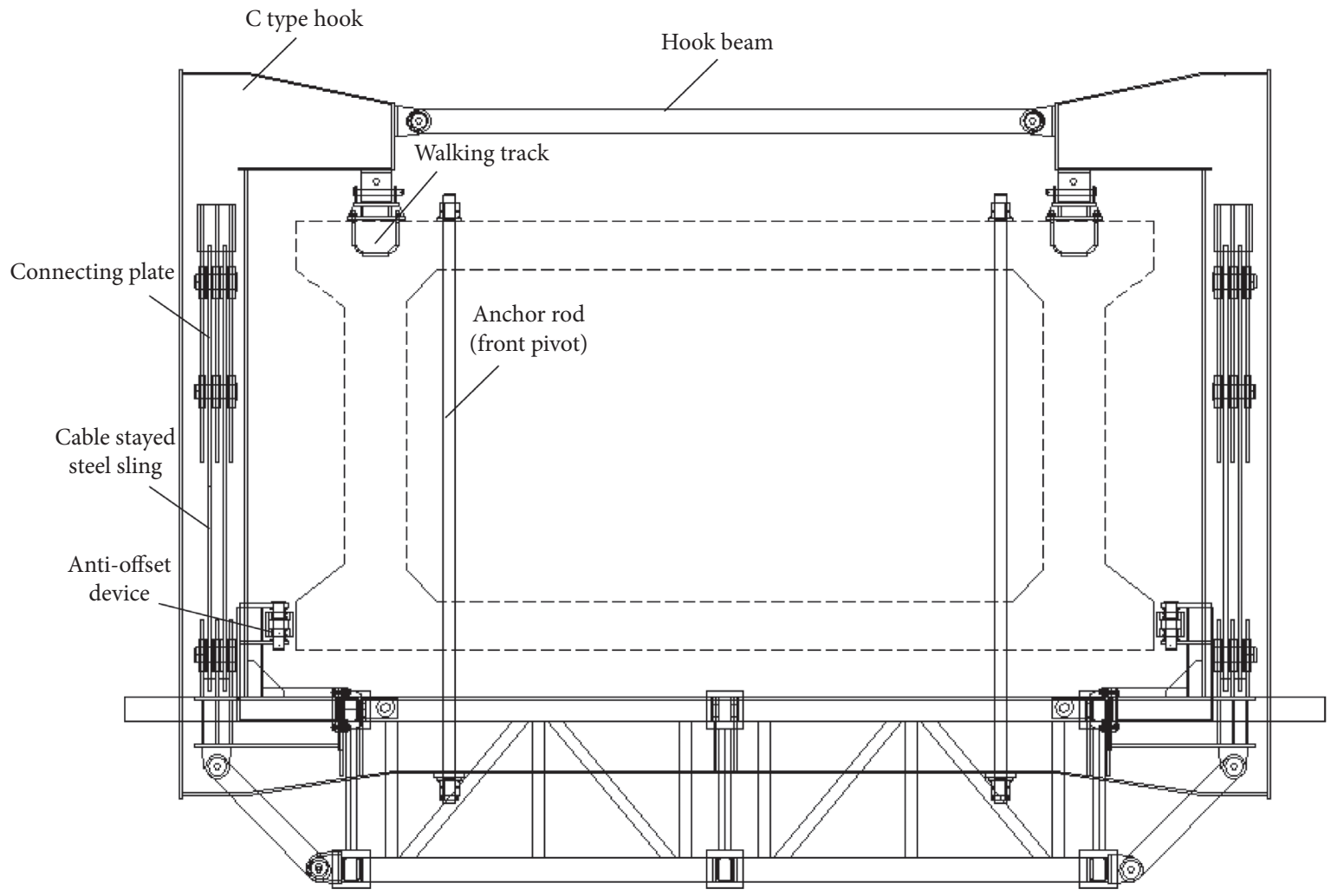

Figure 16: Side view of the new triangular truss hanging basket. 


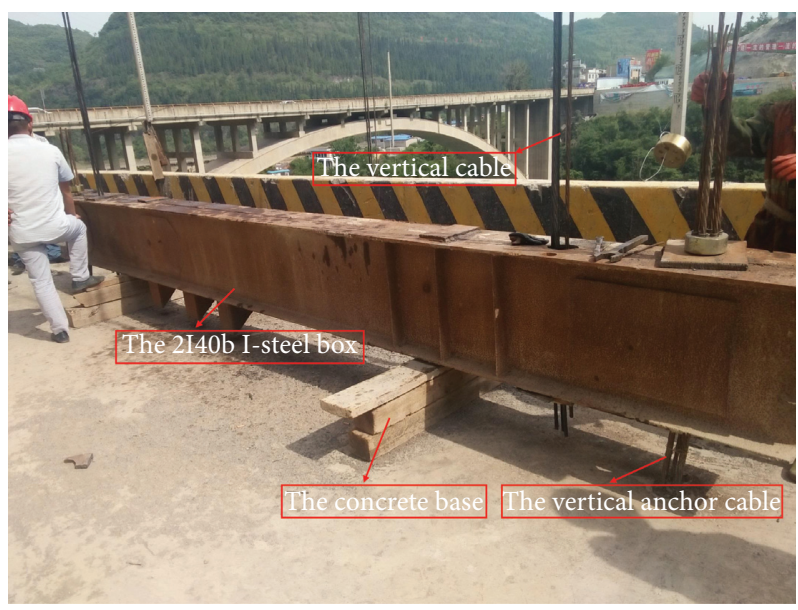

FIgURE 17: Layout of the anchor end of the hanging basket load test.

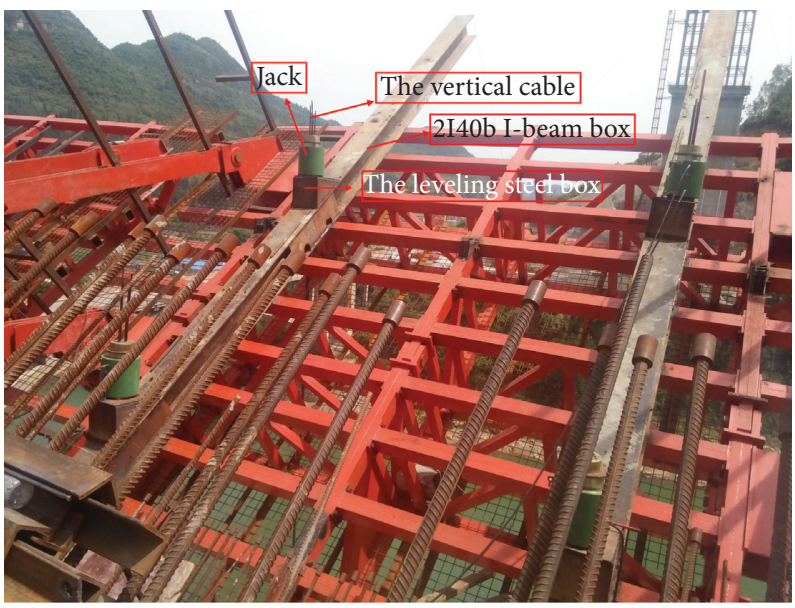

FIgURE 18: Layout of the tension end of the hanging basket load test.

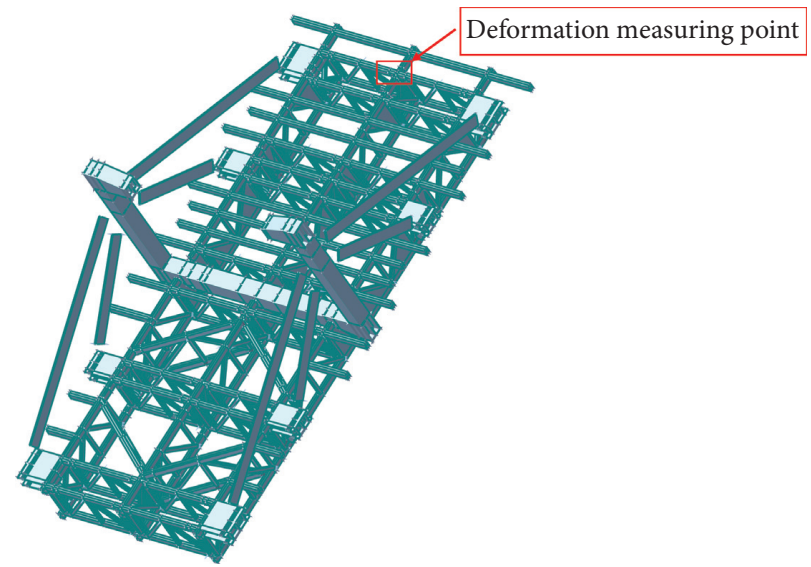

Figure 19: Layout of the deformation measuring point of the hanging basket. 


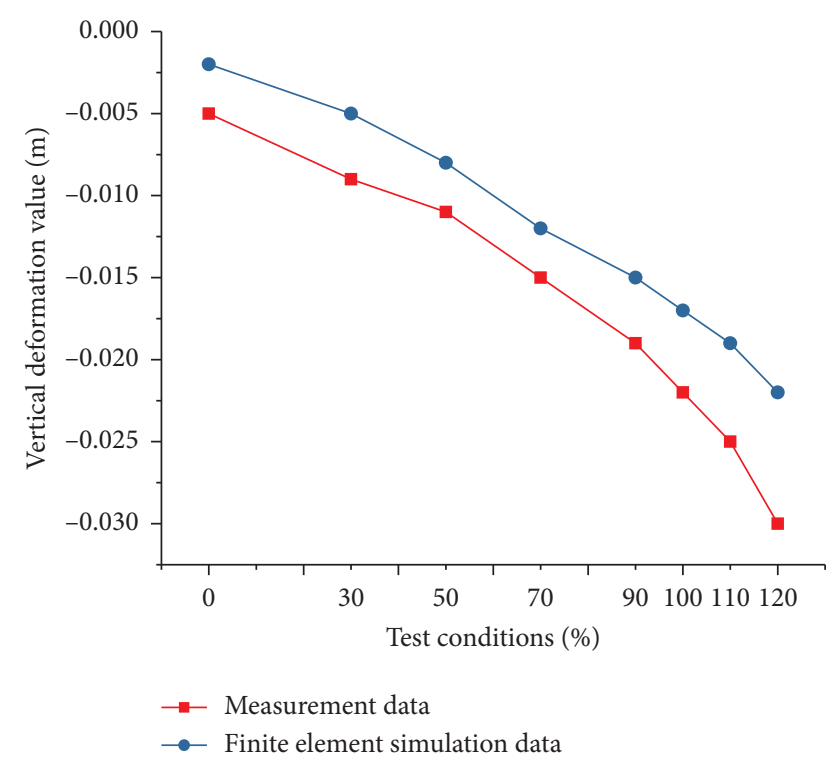

Figure 20: Comparison of the measured value and finite element simulation value.

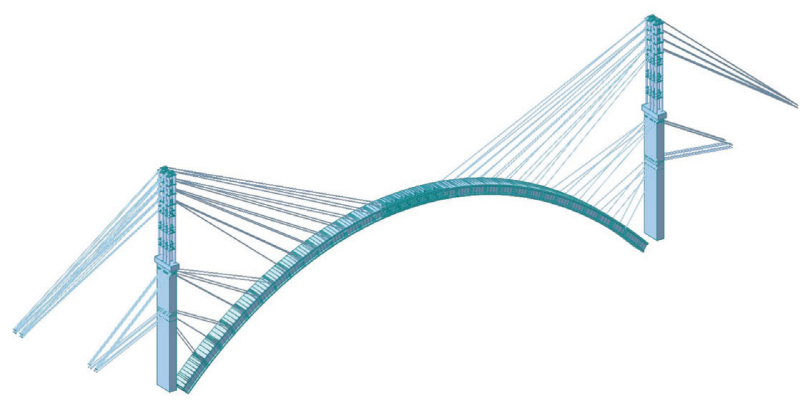

Figure 21: Finite element model of the Yelang Lake Bridge.

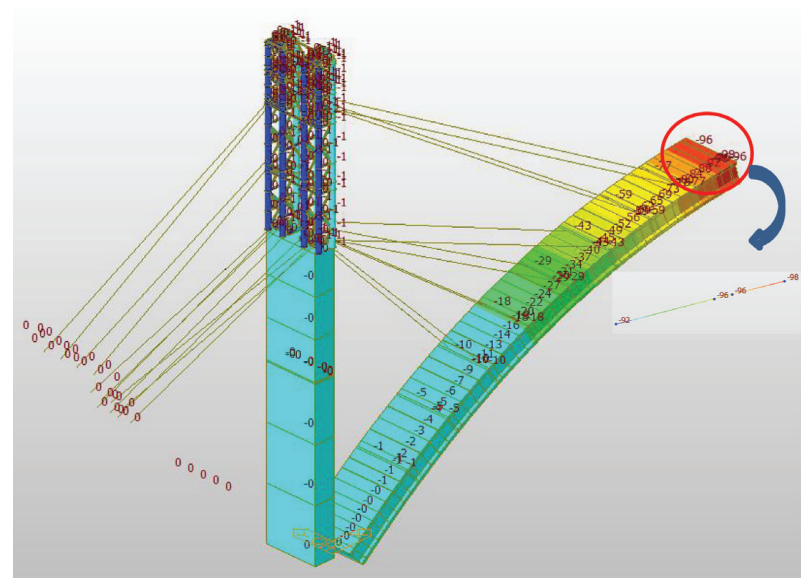

Figure 22: Vertical deformation when pouring concrete.

Through the finite element simulation of the entire arch construction process, the deformation of the arch construction could be obtained, such as the deformation of the arch during pouring of concrete, the deformation when tensioning

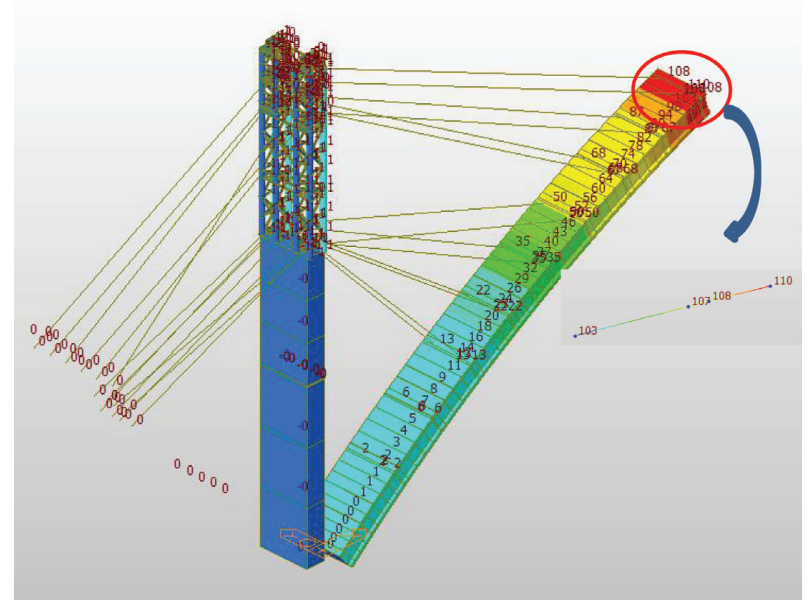

FIGURE 23: Vertical deformation after tensioning buckle cable and anchor cable.

buckle cable and anchor cable, and the deformation of the completed arch construction. These deformations provided guidance for the actual construction of the arch ring.

\subsection{Linear Control Method during Arch Construction.}

The cantilever pouring of the arch ring mainly includes two typical construction stages, namely, the concrete pouring stage of the arch ring segment and the tensioning stage of the buckle cable and anchor cable. Theoretically speaking, as long as the measured deformation in these two typical stages is consistent with the target deformation calculated by the finite element, it can be ensured that the line shape during the construction of the arch ring and the line shape of the arch ring after the completion of the construction are consistent with the target deformation. The target elevation value of the arch ring segment $i$ after pouring is shown in

$$
H_{4}^{i}=H_{2}^{i}+\frac{h}{2} \times \cos \varphi+f_{1}^{i}+\delta^{\prime \prime},
$$

where $H_{4}^{i}$ is the target elevation value of the arch ring segment $i$ after pouring (unit: $\mathrm{m}$ ); $\delta^{\prime \prime}$ is the deformation (vertical displacement) caused by concrete pouring of arch segment $i$, which can be calculated by finite element program (unit: m). Based on Equations (14), (15), and (18), the deviation $\delta$ between the actual deformation value of the arch ring segment and the target value can be known. In Equation (16), considering the deformation deviation $\delta$ produced by the arch ring pouring, it can be ensured that the actual pouring and actual tensioning deformation of the arch ring segment are consistent with the target deformation. Listed below are the deviations between the measured deformation values and the target deformation values when pouring concrete and tensioning buckle cable and anchor cable at sections 2-10 of the left half arch (see Table 1).

It can be seen from Table 1 that during concrete pouring of the arch ring segment, the measured deformation value (downward displacement) of the arch ring segment was greater than the target value, and the maximum difference was $17.1 \mathrm{~mm}$. The deviation value was taken into account 
TABLE 1: Deviation between the measured deformation value and the target deformation value (measured deformation minus target deformation) (mm).

\begin{tabular}{|c|c|c|c|c|c|c|c|c|c|}
\hline Arch segment & 2\# & $3 \#$ & $4 \#$ & $5 \#$ & $6 \#$ & 7\# & $8 \#$ & 9\# & $10 \#$ \\
\hline Deformation difference during concrete pouring & -16.3 & -14.2 & -13.4 & -15.3 & -17.1 & -14.4 & -13.1 & -12.6 & -15.4 \\
\hline Deformation difference of buckle cable and anchor cable when tensioned & -2.9 & -2.4 & 1.7 & 2.5 & 3.1 & -2.7 & 1.9 & -2.2 & 1.8 \\
\hline
\end{tabular}

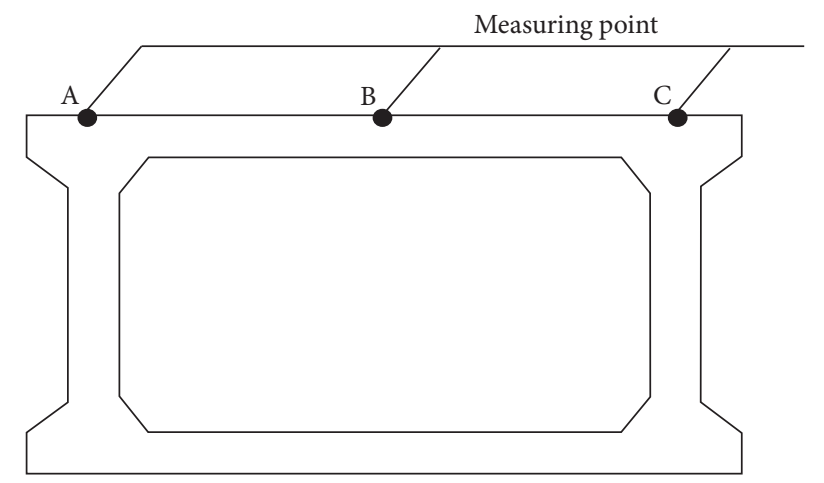

Figure 24: Layout drawing of arch ring elevation measuring point.

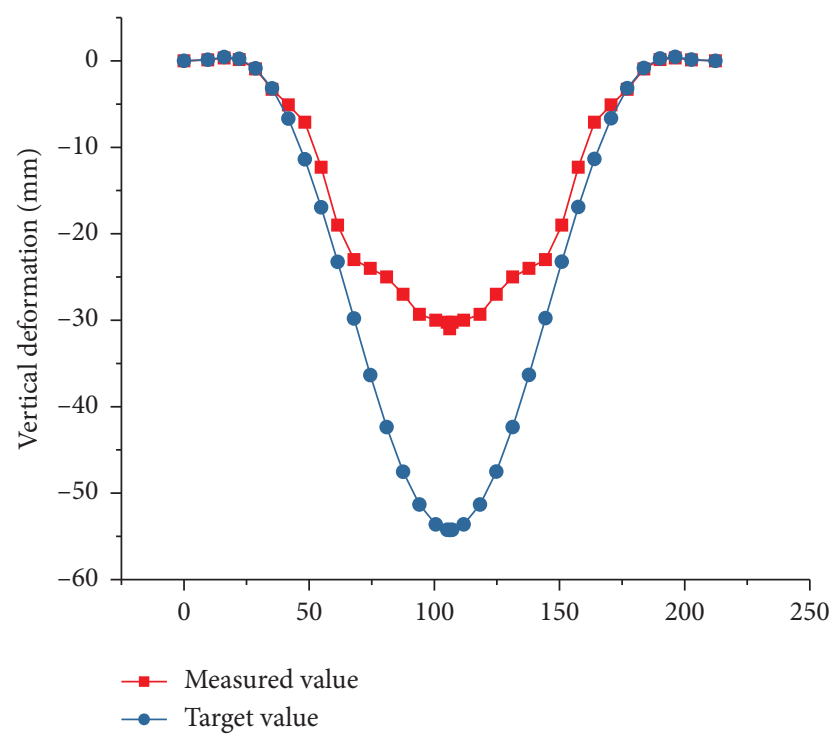

FIgURE 25: Comparison of the measured deformation value and the target deformation value after the arch ring construction is completed.

when tensioning the buckle and anchor cable. After the tensioning was completed, the deviation between the measured deformation value and the target value was at most $3.1 \mathrm{~mm}$.

4.3. Measurement Error Analysis. Affected by the errors of instruments, temperature, measurement personnel, etc., the actual measured elevation of the arch ring is often different from the theoretically calculated elevation. In view of these errors, the reasons must be carefully analyzed during the construction control of the arch ring to ensure the accuracy of the measurement.
4.3.1. Instrument Error. Affected by the measurement accuracy of the instrument, system errors are often caused in the measurement process. Therefore, it is necessary to select a high-precision instrument when measuring the height of the arch ring.

4.3.2. Error Caused by Temperature. The temperature difference of sunlight has a significant impact on the height of the arch, especially since the arch is in a large cantilever state. In order to avoid the influence of sunlight, the arch measurement is often carried out before the sun comes out in the morning. 
4.3.3. The Location of the Measuring Point Must Be Accurate. When measuring the arch ring, the position of the measuring point changes or the position of the measuring point is inconsistent, which will cause a large error in the arch ring elevation, and some errors may even reach more than ten centimeters. In order to solve the measurement error caused by the inconsistency of the measuring point position, a fixed measuring point (see Figure 24) should be set on the arch ring and clearly marked.

4.3.4. Other Measurement Error Analyses. During the concrete pouring of the arch ring segment, if the concrete pouring amount is large and the stiffness of the formwork is small, the actual pouring section of the arch ring will be larger than the theoretical section, which will affect the weight and stiffness of the cantilever arch ring. Therefore, when pouring the arch ring segment, it is necessary to strengthen the stiffness of the formwork and control the amount of concrete pouring.

4.4. Linear Control of the Completed Main Arch Ring Construction. The main arch ring of Yelang Lake Bridge was constructed by using a new triangular truss hanging basket. The new hanging basket has the characteristics of large bearing capacity and high rigidity, which can be well adapted to the large-segment cantilever pouring construction of the arch ring of this bridge, ensuring the cantilever construction quality of the arch ring. In terms of the arch line shape, after the completion of the main arch ring construction, all segments of the arch ring were measured, and the measuring points were arranged on the outside, middle, and inside of the top plate at the end of each segment (see Figure 24). In Figure 25, the measured maximum deformation value was $-30.1 \mathrm{~mm}$, the target maximum deformation value was $-55 \mathrm{~mm}$, and the maximum deviation between the measured deformation value and the target deformation value was only $2.5 \mathrm{~cm}$, which met the requirements of the specification, and it proved that the main arch ring was well controlled. This also showed that the use of formwork positioning equation before concrete pouring of arch ring segment and arch ring elevation calculation equation under two typical working conditions after concrete pouring of arch ring segment and completion of buckle and anchor cable tensioning to control the line shape of the cantilever pouring arch ring was good.

\section{Conclusions}

Yelang Lake Bridge is currently the largest cantilevered single-chamber reinforced concrete arch bridge in China, with a net span of $210 \mathrm{~m}$. Due to the length and weight of the arch ring segment, the linear control of the cantilever pouring of the arch ring is challenging:

(1) This article derived the formwork positioning equation before concrete pouring of arch ring segment and arch ring elevation calculation equation under two typical working conditions after concrete pouring of arch ring segment and completion of buckle and anchor cable tensioning.

(2) The results showed that the arch ring segment elevation calculation equation could effectively ensure the accuracy of the arch ring segment construction process under the two typical working conditions of completion of concrete pouring of the arch ring segment and completion of the buckle and anchor cable tensioning, and the maximum deviation was only $3.1 \mathrm{~mm}$. After the completion of arch ring construction, the line shape was in good agreement with the target line shape, and the deviation between the measured deformation value and the target deformation value was only $2.5 \mathrm{~cm}$, which met the engineering requirements. It shows that the method proposed in this article is effective.

(3) This article introduced a new type of hanging basket and the load test of the hanging basket used in the cantilever pouring of the arch ring. The results showed that the measured deformation value of the hanging basket was very consistent with the finite element value, which can provide a reference for similar projects.

\section{Data Availability}

The experimental data used to support the findings of this study are included in the article.

\section{Conflicts of Interest}

The authors declare that they have no conflicts of interest.

\section{Acknowledgments}

This study was supported by the National Natural Science Foundation of China (U20A20314), the Chongqing Natural Science Foundation of China (cstc2019jcyj-cxttX0004 and cstc2019jscx-gksbX0047), the Science and Technology Project of Hubei Provincial Transportation Department (2020-2-1-1 and 2020-186-1-6), and the Science and Technology Project of Guizhou Provincial Transportation Department (2018-123-001).

\section{References}

[1] M. M. Hassan, A. O. Nassef, and A. A. El Damatty, "Determination of optimum post-tensioning cable forces of cablestayed bridges," Engineering Structures, vol. 44, pp. 248-259, 2012.

[2] M.-H. Ha, Q.-A. Vu, and V.-H. Truong, "Optimum design of stay cables of steel cable-stayed bridges using nonlinear inelastic analysis and genetic algorithm," Structures, vol. 16, pp. 288-302, 2018.

[3] A. Kasuga, H. Arai, J. E. Breen, and K. Furukawa, "Optimum cable-force adjustments in concrete cable-stayed bridges," Journal of Structural Engineering, vol. 121, no. 4, pp. 685-694, 1995. 
[4] J. Wu, D. M. Frangopol, and M. Soliman, "Geometry control simulation for long-span steel cable-stayed bridges based on geometrically nonlinear analysis," Engineering Structures, vol. 90, pp. 71-82, 2015.

[5] D. Bruno, P. Lonetti, and A. Pascuzzo, "An optimization model for the design of network arch bridges," Computers \& Structures, vol. 170, pp. 13-25, 2016.

[6] M. Z. Elrehim, M. A. Eid, and M. G. Sayed, "Structural optimization of concrete arch bridges using genetic algorithms," Ain Shams Engineering Journal, vol. 10, no. 3, pp. 507-516, 2019.

[7] Y.-C. Sung, D.-W. Chang, and E.-H. Teo, "Optimum posttensioning cable forces of Mau-Lo Hsi cable-stayed bridge," Engineering Structures, vol. 28, no. 10, pp. 1407-1417, 2006.

[8] P.-H. Wang, T.-Y. Tang, and H.-N. Zheng, "Analysis of cablestayed bridges during construction by cantilever methods," Computers \& Structures, vol. 82, no. 4-5, pp. 329-346, 2004.

[9] M. F. Granata, G. Longo, A. Recupero, and M. Arici, "Construction sequence analysis of long-span cable-stayed bridges," Engineering Structures, vol. 174, pp. 267-281, 2018.

[10] F. Fabbrocino, M. Modano, I. Farina, G. Carpentieri, and F. Fraternali, "Optimal prestress design of composite cablestayed bridges," Composite Structures, vol. 169, pp. 167-172, 2017.

[11] C. Song, R. Xiao, and B. Sun, "Optimization of cable pretension forces in long-span cable-stayed bridges considering the counterweight," Engineering Structures, vol. 172, pp. 919-928, 2018.

[12] Y. Li, J.-l. Wang, and S.-S. Ge, "Optimum calculation method for cable force of concrete-filled steel tube arch bridge in inclined cable-stayed construction," Journal of Highway and Transportation Research and Development (English Edition), vol. 11, no. 1, pp. 42-48, 2017.

[13] S.-I. Nakamura, H. Tanaka, and K. Kato, "Static analysis of cable-stayed bridge with CFT arch ribs," Journal of Constructional Steel Research, vol. 65, no. 4, pp. 776-783, 2009.

[14] J. H. O. Negrão and L. M. C. Simões, "Optimization of cablestayed bridges with three-dimensional modelling," Computers and Structures, vol. 64, no. 4, pp. 741-758, 1997.

[15] H. J. Kang, Y. Y. Zhao, H. P. Zhu, and Y. X. Jin, "Static behavior of a new type of cable-arch bridge," Journal of Constructional Steel Research, vol. 81, pp. 1-10, 2013.

[16] A. Baldomir, S. Hernandez, F. Nieto, and J. A. Jurado, "Cable optimization of a long span cable stayed bridge in La Coruña (Spain)," Advances in Engineering Software, vol. 41, no. 7-8, pp. 931-938, 2010.

[17] A. M. B. Martins, L. M. C. Simões, and J. H. J. O. Negrão, "Optimization of cable forces on concrete cable-stayed bridges including geometrical nonlinearities," Computers \& Structures, vol. 155, pp. 18-27, 2015.

[18] Y. W. Dai and Y. Y. Wang, "A research to cable force optimizing calculation of cable stayed arch bridge," Procedia Engineering, vol. 37, pp. 155-160, 2012.

[19] D. W. Chen, F. T. K. Au, L. G. Tham, and P. K. K. Lee, "Determination of initial cable forces in prestressed concrete cable-stayed bridges for given design deck profiles using the force equilibrium method," Computers \& Structures, vol. 74, no. 1, pp. 1-9, 2000.

[20] P. H. Wang, T. C. Tseng, and C. G. Yang, "Initial shape of cable-stayed bridges," Computers \& Structures, vol. 47, no. 1, pp. 111-123, 1993.

[21] J. Zhang and F. T. K. Au, "Calibration of initial cable forces in cable-stayed bridge based on Kriging approach," Finite Elements in Analysis and Design, vol. 92, pp. 80-92, 2014.
[22] D. Janjic, M. Pircher, and H. Pircher, "Optimization of cable tensioning in cable-stayed bridges," Journal of Bridge Engineering, vol. 8, no. 3, pp. 131-137, 2003.

[23] M. F. Granata, P. Margiotta, A. Recupero, and M. Arici, "Partial elastic scheme method in cantilever construction of concrete arch bridges," Journal of Bridge Engineering, vol. 18, no. 7, pp. 663-672, 2013.

[24] Z.-C. Tian, W.-P. Peng, J.-R. Zhang, T.-Y. Jiang, and Y. Deng, "Determination of initial cable force of cantilever casting concrete arch bridge using stress balance and influence matrix methods," Journal of Central South University, vol. 26, no. 11, pp. 3140-3155, 2019. 